\title{
The Cognitive Awareness Among Students of the Faculty of Nursing Towards Mentally Handicapped Individuals in Kuwait
}

\author{
Ahmed Mohsen Al - Saeedi ${ }^{1}$, Abdulaziz Sadiq Alawadh ${ }^{1}$, \& Saleh H. AL-Anezi ${ }^{1}$ \\ ${ }^{1}$ Public Authority of Applied Education, College of Basic Education, Kuwait \\ Correspondence: Ahmed Mohsen Al - Saeedi. E-mail: ahmed_alsadiey@yahoo.com
}

Received: March 9, 2020

Accepted: May 5, 2020

Online Published: July 31, 2020

doi:10.5539/ass.v16n8p148

URL: https://doi.org/10.5539/ass.v16n8p148

\begin{abstract}
The current study aimed to know the cognitive awareness among students of the faculty of nursing towards mentally handicapped individuals in Kuwait and its relationship with some other variables, this study was conducted on a sample of (224) students of the faculty of nursing the Public Authority for Applied Education. The Faraj (2016) scale was applied to the study sample, the results of the study indicated that the total average score was (1.89) and the percentage was (63.10\%), which is considered a low score in the knowledge and awareness of the students of the Faculty of Nursing, and the results indicated that there are no statistically significant differences between the students of the Faculty of Nursing in other variables.
\end{abstract}

Keywords: Cognitive awareness, Nursing, Disabled

\section{Introduction}

Recently, States have become interested in providing all health, psychological and social services to persons with disabilities in various categories, and working to communicate with them to facilitate procedures to ensure their integration into the society in which they live along with their ordinary peers (Al-Kenani, 2009).

Among the needs that have increased attention in recent times is the nursing care of disabled individuals and the great and necessary importance of this profession and its affiliates in supporting the disabled and mitigating them and interacting with them and helping them by trying to integrate them with other members of society, which is based on the scientific basis that who works in the nursing profession is required to assessing the general needs of the disabled, whether it is physical, psychological or social and planning it and then implementing what was planned (Al-Dughaim, 2017).

Nursing as a profession is concerned with the need to take care of every person, whether this person is healthy or not. All the more for the disabled person, which makes the nursing system the basic segment, which must be present within the multidisciplinary medical team, which generally seeks to provide medical and nursing elements to all members of the community without exception (Albatsh \& Petro, 1997).

Children with disabilities generally suffer from several health problems, requiring constant review of medical centers and hospitals to provide them with health care, while at the same time being trained even if it was in a simple way on self-care and social skills required from them (Fisher et al., 2008).

Institutions who is taking care of people with disabilities in most countries of the world are keen on the participation of nurses in the membership of the Disability Personnel Services Team, to help people with disabilities regain their physical and health capacities, diagnose health problems in collaboration with doctors, follow up cases and contribute to the prevention of complications and various problems (Khan, 1988).

Therefore, the nursing profession is one of the most important support services that must be provided to the disabled. In spite of the human dimension of the nursing profession, some studies indicate that the awareness and knowledge of nurses towards individuals with disabilities is low, weak and confused with various disabilities, which affects the quality of services provided and the opportunities offered to these disabled people (1994, Gething). Examples of such studies is the studies of Oremann, Biordi (1995), Shaw (1995, Judy) and Judy (2007), all of which indicated that the lack of knowledge and awareness of nurses towards disabled individuals, and that most nurses They were not comfortable working with them and had negative attitudes towards them Even at the level of nursing students they were have smattering that is dominated by ignorance and randomness to them, and explains that the lack of information and basic facts about individuals with disabilities and the lack 
of ways to communicate with them by nurses about these disabled individuals (Jaradah, 2005).

Perhaps the beginning of this knowledge lies in knowing the nature of the study in the faculty, and the quality of the courses that are given to the students of the Faculty of Nursing during the study, so that the service becomes available to all individuals without exception on different forms, colors and disabilities, taking into account the individual differences between individuals and equality between them without discrimination.

It is clear from the above that there is a need in the research and investigation of the degree of cognitive awareness of nurses towards disabled individuals to be practicing the profession acceptable in the community.

Hence the idea of the study emerged in the knowledge of the degree of cognitive awareness among students of the Faculty of Nursing towards individuals with disabilities in Kuwait.

Questions of the Study:

1. What is the level of cognitive awareness among students of the Faculty of Nursing affiliated to the Public Authority for Applied Education in Kuwait?

2. Does the degree of cognitive awareness among the students of the Faculty of Nursing affiliated to the Public Authority for Applied Education at the level of significance $(\alpha 0.05)$ according to the variables of sex, grade and other?

\section{Purpose of the Study}

The purpose of this study is to try to assess the reality of the knowledge of nursing students towards the mentally handicapped individuals the students' knowledge about this mentally handicapped child and the social and demographic characteristics such as: sex and schooling.

The importance of study:

The importance of the study follows the importance of the role of the nurse towards health care for the mentally handicapped. Its importance also comes from the fact that it focuses on measuring the knowledge and awareness of the students towards the mentally handicapped as one of the team members working with these handicapped after their graduation.

\section{Literature Review}

Abdel Fattah \& Suhail (2018) conducted a study entitled "Teachers' attitudes towards the integration of students with disabilities with their peers in the governmental schools of Salfit Governorate". This study aims to examine the teachers' attitudes towards the integration of students with disabilities with their peers in the governmental schools of Salfit Governorate, and also to recognize the level of their acceptance of this integration process on the basis of some variables: (gender, academic qualification, years of experience, marital status, and the existence of a student with disability in the teacher's family). For achieving the study objectives, the researcher used the analytical descriptive approach, and she developed a questionnaire which included (45) paragraphs distributed into three fields. The first field: the experiences and training of teachers; the second field: the attitudes towards the circumstances and the environment which support the integration of people with disabilities; the third field: the attitudes towards the social and psychological aspects of dealing with people with disabilities and their families. The study was applied to a stratified random sample consists of (200) male and female teachers representing (52.3\%) of the study population which consists of (382) male and female teachers of the lower primary stage at the governmental schools of Salfit Governorate, according to the statistics of the Directorate of Education. After questionnaires were collected, they were statistically processed by using arithmetic means, percentages and standard deviations as well as level of significance. The study concluded that the total degree of teachers' responses to all paragraphs of the questionnaire was positive; as the percentage of participants' responses to these paragraphs was (66.4\%), and there were no statistically significant differences in the teachers' attitudes towards the integration of students with disabilities with their peers in governmental schools to be attributed to the variables of academic qualification and years of experience, as well as the existence of a student with disability in the teacher's family. The findings indicated that there are differences in teachers' attitudes towards the integration of students with disabilities with their peers in the governmental schools of Salfit Governorate to be attributed to the gender variable; as differences were in favor of females. Furthermore, the findings indicated that there are differences in teachers' attitudes towards the integration of students with disabilities with their peers in the governmental schools of Salfit Governorate to be attributed to marital status variable, and the differences were in favor of the "married" category. Based on discussing these findings, the researcher recommended to carry out further studies on the philosophy of integration, preparing and qualifying teachers in advance with regards to the integration process, providing special resource rooms in the 
schools for students with disabilities, as well as increasing incentives for teachers working in the field of education for people with disabilities.

Matrood (2018) conducted a study entitled "The role of culture in developing security awareness among university students/Field social study at the University of Babylon". He stated that culture is an active and vital factor in the advancement of human societies through its main role in improving social behavior and building a knowledge system that contributes to the creation of a conscious generation that serves the law, ethics, beliefs and customs prevailing to achieve a state of security and stability that meets the different human needs. The legitimacy of the students is a wide spectrum in society and it is up to them to build the country, which requires an exceptional effort in the characterization of the student and his awareness of his responsibilities in protecting social institutions and promoting them and the concept of security awareness to achieve social welfare and stability.

Al-asqa (2018) conducted a study entitled "The effectiveness of a knowledge-based program to modify the attitudes of ordinary students toward students with intellectual disabilities in mainstream schools". The purpose of this study is to identify the effectiveness of cognitive behavioral program in modifying negative attitudes of female students towards their peers with intellectual disability in primary inclusive school in Riyadh, Saudi Arabia. The study used quasi-experimental method, and simple random sample consist of (40) students, randomly distributed, the experimental group was (20) students, and the control group was (20) students, their ages between (9-12) years, the instruments were: attitude toward disability scale designed by Althebiany [1] cognitive behavioral program designed by the researcher, the program included (12) session, (2) session per week, which applied with experimental group only. $\mathrm{T}$ test was used for data analysis. The results showed statistically significant difference between pre and post measurement favor of post-test of the experimental group's students who have been involved in program sessions, also showed statistically significant difference between experimental and control group favor experimental group. The results revealed the effectiveness of the cognitive behavioral program in modifying negative attitudes among female students toward their peers with intellectual disabilities in primary integrated schools. Several recommendations emerged, the most important is using this program for enhancing attitudes towards students with disabilities in integrated school before applying the integration.

A study of Othman and Mubaraki (2017) investigated the trends of children's teachers and their families enrolled in kindergarten towards the educational integration of people with disabilities, with ordinary children in kindergarten, the study sample consisted of (63) of families with unusual children in kindergarten, and (94) of female teachers working with children in kindergarten, where the questionnaire tool was used to collect data to measure the trends of children's teachers and their families towards the educational integration of people with disabilities in children kindergarten, after the statistical analysis, the results found that there is a positive trend towards the inclusion of the extraordinary child with acceptance of educational inclusion from the point of view of the average child from the point of view of the two study groups, and that most teachers' disabilities are children with simple mental disabilities, and hearing disabilities, the study recommended working to integrate extraordinary children in kindergarten with ordinary children, and work to prepare qualified teachers to deal with children in the kindergarten in which the inclusion system is applied.

Al-Atrash (2016) study expanded to identify the trends of physical education teachers and their teachers, and to integrate students with disabilities in the physical education class with regular students in government schools in Jenin Governorate, and the researcher used the descriptive approach to suit his study objectives, a questionnaire was distributed that measures the attitudes of teachers towards integrating students with disabilities with ordinary students, and the questionnaire included three dimensions: (psychological, social, and academic), and the study sample consisted of (20) teachers who are studying physical education in the Jenin Governorate The results showed that there are positive trends among physical education teachers and their teachers, and the integration of students with disabilities with regular students.

Al-A'dra (2016) conducted a study entitled " Challenges Facing Students with Disabilities at the University of Jordan: A Field Study". The study deals with administrative, academic, environmental and social difficulties faced by students with disabilities at the University of Jordan, As well as to identify the general characteristics of those students enrolled at the university for the academic year 2014/2015. The study data were collected using questionnaires filled during personal interviews with a sample of students, selected randomly, using social survey methodology totaling (81) students who represent $19 \%$ of the total number registered in the Student Counseling Department at Deanship of Student Affairs. The questionnaire was developed according to a five-numbered scale. Results were analyzed using the SPSS program. Descriptive statistics were provided to describe data. The results of the current study indicate that students with disabilities encounter many 
administrative difficulties in registration procedures due to the lack of academic guidance and inadequate procedures, in addition to learning difficulties such as competing with non-disabled students, performance during examinations and difficulties in comprehending the educational material. Furthermore, there are environmental difficulties in the form of: the lack of adequate reading holes at the library, difficulties in participating in university activities, lake of accessibility on sidewalks. Social difficulties are also present in the form of: failure to get teachers' assistant concerning their circumstances and the negative attitudes of their non-disabled colleagues. Results show no statistically significant differences in difficulties encountered by students attributed to the variables: sex, place of residence and faculty. There are also statistically significant differences attributed to educational level in favor of the fourth year only, and to the type of disability in the area of environmental difficulties in favor of physical disability only. The study proposed a number of recommendations including: work more on accessibility issues at the university environment to accommodate students with disabilities and to amend certain laws and regulations at the university to meets their needs.

\section{Methodology}

This descriptive and analytical study was conducted, which included (224) students of the Faculty of Nursing of the Public Authority for Applied Education in order to assess the knowledge in the degree of cognitive awareness of these students to the mentally handicapped child and to identify the relationships between their knowledge and demographic characteristics, as of January 15, 2019 until 15 July 2019. A random sample of students (male and female) was selected. The researcher used Faraj (2016) scale for this study, which derived most of its items through the study of Bi, (2010) as well as the study of Kitchen, (2007) The researcher translated this measure into Arabic, and consists of two parts: the first includes demographic data, and the second part includes 18 questions to measure the degree of cognitive awareness of students of the Faculty of Nursing towards the disabled child. These questions were classified on the tripartite Likert scale (I agree, uncertain, disagree), and each answer was given the following (3,2 and 1), and the degree of cognitive awareness among nursing students was classified according to the following data: Less than (66.6\%) A low degree of cognitive awareness $(66.7 \%$ $77.7 \%$ ) was an average degree in cognitive awareness, while $(77.7 \%-100 \%)$ was a high degree of cognitive awareness. This measure was distributed to the study sample and was given a period of time (15-20) minutes to answer the questions, and determine the validity of the content of the scale after its translation into Arabic, and through the presentation of a group of arbitrators in the College of Basic Education Special education, so as to check the clarity and appropriateness of the questionnaire to achieve the objectives of the current study, suggestions were taken into account, the use of adjustments and complete the final version of the measure, which was built to be the appropriate tool for the study.

The internal consistency of the scale was determined by calculating the alpha correlation coefficient (Cronbach alpha), and the reliability result $(\mathrm{r}=0.70)$ was considered statistically appropriate, which means that the scale has sufficient level of internal consistency. Statistical analyzes were performed using the Statistical Package for Social Sciences (SPSS) version 21. Data analysis was used by applying descriptive and deductive statistical approaches.

\section{Results and Discussion}

First: Description of the study sample:

Table 1. Distribution of Students by their Socio-demographic Characteristics N=224

\begin{tabular}{cccc}
\hline & & Frequency & Percent \\
\hline \multirow{2}{*}{ Gender } & male & 27 & $12.1 \%$ \\
& female & 197 & $87.9 \%$ \\
& Total & 224 & 100.0 \\
\hline \multirow{2}{*}{ Scholastic stage } & first & 149 & $66.5 \%$ \\
& second & 75 & $33.5 \%$ \\
& Total & 224 & 100.0 \\
\hline \multirow{2}{*}{ Having mentally disabled child as family member } & YES & 14 & $6.3 \%$ \\
& NO & 210 & $93.8 \%$ \\
& Total & 224 & 100.0 \\
\hline
\end{tabular}

The above table indicates that the study included (224) male and female students from the Faculty of Nursing, $(12,1 \%)$ were males and $(87,9 \%)$ were females. This result explains that the percentage of female graduates from high school is higher than male percentage, and it shows that females prefer this kind of professions compared to 
males. The table indicates that there are $(66.5 \%)$ of the students in the first year only, and $(33.5 \%)$ of the students in the second year, due to the nature of the study in this stage (diploma stage) in which the student spends two years of study, and the difference between the first and second year is that the withdrawal occurs among the students during their first year of study at this faculty. The table also indicates that $(93.8 \%)$ of the students do not have a child with mental disabilities in the family, while $(6.3 \%)$ of the students have a child with mental disabilities in the family.

Second: Answer to the first question of the study:

What is the level of awareness among students of the Faculty of Nursing, which works under the office of the Public Authority for Applied Education in Kuwait?

Table 2. Mean of Scores and Relative Sufficiency for Undergraduate Nursing College Students towards Mentally Disabled Child

\begin{tabular}{|c|c|c|c|c|c|}
\hline $\mathrm{M}$ & Items & Mean & $\begin{array}{c}\text { Std. } \\
\text { Deviation }\end{array}$ & $\mathrm{RS} \%$ & Grade \\
\hline 1 & Mentally handicapped children are as smart as normal kids & 1.72 & 0.74 & $\% 57.44$ & $\mathrm{~L}$ \\
\hline 2 & $\begin{array}{l}\text { Dealing with mentally handicapped children is usually easier than dealing } \\
\text { with ordinary children }\end{array}$ & 1.67 & 0.78 & $\% 55.80$ & $\mathrm{~L}$ \\
\hline 3 & Most mentally handicapped children feel distressed for themselves & 2.04 & 0.81 & $\% 68.01$ & M \\
\hline 4 & $\begin{array}{l}\text { Parents of mentally handicapped children should be less strict than those of } \\
\text { ordinary children }\end{array}$ & 1.55 & 0.81 & $\% 51.79$ & $\mathrm{~L}$ \\
\hline 5 & Mentally handicapped children don't differ from other children & 1.89 & 0.92 & $\% 62.95$ & $\mathrm{~L}$ \\
\hline 6 & There should be no special school for mentally handicapped children & 1.39 & 0.74 & $\% 46.28$ & $\mathrm{~L}$ \\
\hline 7 & Care for mentally handicapped children is up to the government & 2.42 & 0.77 & $\% 80.65$ & $\mathrm{H}$ \\
\hline 8 & $\begin{array}{l}\text { Mentally handicapped children are expected to adhere to the same } \\
\text { standards as non-handicapped children }\end{array}$ & 1.71 & 0.82 & $\% 57.14$ & $\mathrm{~L}$ \\
\hline 9 & Mentally handicapped children are as happy as non-handicapped children & 1.55 & 0.67 & $\% 51.79$ & $\mathrm{~L}$ \\
\hline 10 & $\begin{array}{l}\text { It is almost impossible for mentally handicapped children to lead a normal } \\
\text { life }\end{array}$ & 2.41 & 0.75 & $\% 80.36$ & $\mathrm{H}$ \\
\hline 11 & You shouldn't expect that much from mentally handicapped children & 2.35 & 0.80 & $\% 78.42$ & $\mathrm{H}$ \\
\hline 12 & Mentally handicapped children tend to protect themselves most of the time & 1.74 & 0.73 & $\% 58.04$ & $\mathrm{~L}$ \\
\hline 13 & $\begin{array}{l}\text { Children with mental disabilities are more irritable than non-disabled } \\
\text { children }\end{array}$ & 2.31 & 0.75 & $\% 76.93$ & M \\
\hline 14 & Mentally handicapped children cannot lead a normal social life & 2.34 & 0.83 & $\% 78.13$ & $\mathrm{H}$ \\
\hline 15 & $\begin{array}{l}\text { Mentally handicapped children feel that they are not as efficient as other } \\
\text { children }\end{array}$ & 1.97 & 0.79 & $\% 65.77$ & $\mathrm{~L}$ \\
\hline 16 & $\begin{array}{l}\text { You have to be careful of what you say when you are with mentally } \\
\text { handicapped children }\end{array}$ & 1.21 & 0.53 & $\% 40.18$ & $\mathrm{~L}$ \\
\hline & Total & 1.89 & 0.76 & $\% 63.10$ & \\
\hline
\end{tabular}

Low = Less than (66.66): Moderate (66.66- 77.77): High (77.78- 100.0).

The above table indicates that the overall average of the degree of perception and knowledge of the phrases (16) with regard to cognitive awareness among students of the Faculty of Nursing at the diploma stage towards the mentally handicapped child, to the presence of a low level of cognitive awareness among students with regard to their knowledge of the mentally handicapped child, The results showed that the total average score was (1.89) and a percentage $(63.10 \%)$, which represents a low degree of cognitive awareness. Four of the phrases received a high degree of cognitive awareness (7-10-11-14). These phrases are common and familiar in general knowledge. There are only two phrases that got an average level of cognitive awareness, namely, phrase (3-13), which referred the emotional side of the students of the Faculty of Nursing. The remaining 10 phrases had a low degree of cognitive awareness (phrases: 1, 2,4,5,6,8,9,12,15 and16), which were referring to the general characteristics of general knowledge regarding the nature of the disabled child, in the end the previous table indicates a general weakness in the level of cognitive awareness. This may seem acceptable, because the students of the Faculty of Nursing do not study courses in the education of disabled people or psychology and mental health, which contributes to the formation in the presence of general weakness in the awareness of cognitive towards disabled people, and the formation of negative thoughts about them, and these findings are consistent with the study Oremann, Biordi (1995), Shaw (1995), and Judy (2007, Judy), all of which indicated that the degree of cognitive 
awareness is low among nurses towards disabled individuals.

Third: Answer to the second question of the study: Does the degree of cognitive awareness among students of the Faculty of Nursing at the level of significance $(\alpha 0.05)$ according to the variables of sex, grade and others?

Table 3. T-test for Socio-demographic Characteristic

\begin{tabular}{ccccccccc}
\hline & & $\mathrm{N}$ & Mean & Std. Deviation & $\mathrm{T}$ & df & Sig & level sig \\
\hline \multirow{2}{*}{ Gender } & Male & 27 & 33.81 & 6.30 & \multirow{2}{*}{0.983} & 222 & 0.326 & Not Sig \\
& Female & 197 & 32.85 & 4.52 & & & \multirow{2}{*}{ Not Sig } \\
\multirow{2}{*}{ Year } & first year & 149 & 32.64 & 4.60 & -1.469 & 222 & 0.143 & \\
& second year & 75 & 33.63 & 5.06 & & & \multirow{2}{*}{ Not Sig } \\
& Yes & 14 & 31.43 & 7.48 & -1.250 & 222 & 0.213 \\
\hline
\end{tabular}

Table 3 shows through (t-test) that there is no statistical significance at the level of $(0.05)$ between the three variables in terms of sex and school stage, as well as the presence of a disabled child within the family environment. This indicates that each sample of the study did not show any significant statistical differences at the level (0.05) in knowledge towards the disabled child.

The researcher explains that the study in the faculties of nursing in Kuwait, does not distinguish between students, whether male or female, for the sake of equal opportunities and gender equality, and that all nursing students, whether male and female, are subject to the same courses and the same programs in college, under the same training conditions in hospitals.

In light of the results of the study, a set of educational recommendations can be presented to the authorities in order to increase the cognitive awareness of the students of the Faculty of Nursing towards mentally handicapped individuals.

- The faculties of nursing should be interested in adding a course for students about those with special needs in terms of identifying them, checking them and how to interact and deal with them, in a way that contributes to the development of knowledge towards those with special needs in general and the mentally disabled in particular.

- The Faculty of Nursing should be interested in adding a course to develop communication skills with the mentally handicapped.

- Increasing media awareness of the categories of the mentally disabled and how to interact and deal with them in a way that contributes to the development of the attitudes of society members towards the disabled in general.

- Conducting studies similar to the current study on male and female students of other colleges.

\section{References}

Abdel Fattah, A., \& Suhail, T. (2018). Teachers' attitudes towards the integration of students with disabilities with their peers in the governmental schools of Salfit Governorate (Unpublished master thesis). Al-Quds Open University

Al-A'dra, I. (2016). Challenges Facing Students with Disabilities at the University of Jordan: A Field Study. Dirasat for Humanities and Social Sciences, 43(5).

Al-asqa, S. (2018).The effectiveness of a knowledge-based program to modify the attitudes of ordinary students toward students with intellectual disabilities in mainstream schools. Global Institute for Study and Research Journal (GISR-J), 4(2).

Al-Atrash, H. (2016). Attitudes of teachers and teachers of physical education towards integrating students with disabilities in the share of physical education with ordinary students in government schools in the Jenin Governorate. Journal of the Federation of Arab Universities for Research in Higher Education, 36(1).

Albatsh, M., \& Petro, W. (1997). Attitudes of the University of Jordan Students Toward the Nursing Profession and its Workers. Educational Sciences Studies, 124(2), 269-282.

Al-Dughaim, M. D. (2017). Students of the College of Nursing Attitudes Towards the Behavior of Assistance. Childhood and Education Journal. Alexandria University, College of Kindergarten: Egypt

Al-Kenani, R. A. (2009). Effectiveness of a proposed program to develop the attitudes of nursing students in Jordanian universities towards the disabled and its effect on developing their communication skills 
(Unpublished doctoral thesis). Amman Arab University: Jordan

Bi, H. (2010). Chinese graduate students'attitudes toward persons with intellectual disabilities: an acculturation approach (Doctoral dissertation, Bowling Green State University).

Faraj, R. K. (2016). Assessment of Undergraduate Nursing Students' Perception towards Mentally Disabled Child. kufa Journal for Nursing sciences, 6(2), 105-111.

Fisher, M. H., Hodapp, R. M., \& Dykens, E. M. (2008). Child abuse among children with disabilities: What we know and what we need to know. International review of research in mental retardation, 35, 251-289.

Jaradah, K. (2005). Building a training program based on therapeutic communication with nurses working in intensive care units in Jordanian government hospitals and explaining the impact of their development (unpublished doctoral thesis). Amman Arab University: Jordan.

Khan, M. H. (1988). The attitudes of male and female students of secondary nursing institutions towards a career in Saudi Arabia. Gulf Letter No. 27, Riyadh

Kitchen, S. G. (2007). Perception of students with disabilities: An assessment of attitudes held by pre-service teachers. West Virginia University.

Matrood, A. (2018). The role of culture in developing security awareness among university students/Field social study at the University of Babylon. Journal of the College of Basic Education for Educational and Human Sciences / University of Babylon, 39(1).

Othman and Mubaraki. (2018). Attitudes of female teachers and families of children towards educational integration in kindergarten, the first international conference for the faculty of kindergarten entitled: Building a better child in light of contemporary variables. Assiut University, 6-7 / 2/2

\section{Copyrights}

Copyright for this article is retained by the author(s), with first publication rights granted to the journal.

This is an open-access article distributed under the terms and conditions of the Creative Commons Attribution license (http://creativecommons.org/licenses/by/4.0/). 